\title{
KLASIFIKASI PENERIMAAN MOBIL BEKAS BERDASARKAN METODE NEURAL NETWORK
}

\author{
Akmal Dirgantara1; Syarifudin Herdyansyah²; Rasenda $^{3}$ \\ Ilmu Komputer \\ STMIK Nusa Mandiri \\ www.nusamandiri.ac.id \\ 114112273@nusamandiri.ac.id; 214002271@nusamandiri.ac.id; 314002279@nusamandiri.ac.id
}

\begin{abstract}
Considering the need for cars in big cities is increasing and the price of 4-wheeled vehicles is relatively expensive, used cars are a good alternative solution to offer. But in business we cannot just buy stock for a car showroom, for example, especially with a limited budget, car showroom entrepreneurs must do a thorough analysis to save the budget to open a showroom and prevent losses. This article helps open the car showroom to determine which cars are suitable as stock to be displayed in the showroom with the parameters of buying, maintenance, doors, boot lugs, and safety. That predicted using 1728 artificial neural network methods data obtained from the UCI repository with a fairly high degree of accuracy that is equal to 98.26\%. This is quite efficient compared to the showroom owner who must conduct a survey in advance and ask 1 per 1 person to survey the interest in receiving a car.
\end{abstract}

Kata Kunci: neural network, used car, Backpropagation, rapidminer, classification.

\begin{abstract}
Abstrak
Mengingat kebutuhan mobil di kota-kota besar semakin meningkat dan harga kendaraan roda 4 yang terbilang mahal maka mobil bekas menjadi alternatif solusi yang baik untuk ditawarkan. Namun dalam berbisnis kita tidak bisa asal saja membeli stok untuk showroom mobil misalnya apalagi dengan budget yang terbatas, pengusaha showroom mobil harus melakukan analisa yang mendalam untuk menghemat budget membuka showroom dan mencegah kerugian. Tulisan ini membantu pembuka showroom mobil menentukan mobil mana saja yang cocok dijadikan stok untuk dipajang pada showroom dengan parameter buying, maintenance, doors, lugs boot dan safety. Yang diprediksi menggunakan metode jaringan syaraf tiruan sebanyak 1728 data yang didapatkan dari UCI repository dengan tingkat akurasi yang cukup tinggi yaitu sebesar 98,26\%. Hal ini cukup efisien dibandingkan pemilik showroom harus melakukan survey terlebih dahulu dan bertanya pada 1 per 1 orang untuk melakukan suvey keminatan penerimaan mobil.
\end{abstract}

Kata Kunci: jaringan syaraf tiruan, mobil bekas, Backpropagation, rapidminer, klasifikasi.

\section{PENDAHULUAN}

Saat ini kebutuhan akan kendaraan di kotakota besar meningkat. Namun, harga kendaraan yang masih terbilang mahal menjadi alasan banyak orang menjadikan mobil bekas sebagai alternatif. Orang-orang sekarang cenderung tidak ambil pusing. Selama kondisi kendaraan masih baik dan bisa digunakan dengan aman, mereka akan mengambilnya (Ika, 2017).

Maka dari itu membuka bisnis mobil bekas merupakan pilihan yang cukup baik untuk dipertimbangkan. Namun untuk membuka sebuah showroom, dibutuhkan analisa pasar untuk menentukan mobil mana yang akan terjual laku ataupun tidak, namun ketika membuka showroom mobil bekas diperlukan analisa pasar yang berbeda, analisa pasar tersebut dapat ditentukan dari peminatan pembelian mobil pada data yang telah ada untuk menentukan seberapa minatnya calon pelanggan yang akan membeli mobil bekas tersebut.

Pada penelitian ini penulis menggunakan metode jaringan syaraf tiruan (Pakaja, Naba, \& Purwanto, 2012), (Guntoro, Costaner, \& Lisnawita, 2019) dari data yang ada. Jaringan syaraf tiruan merupakan salah satu sistem pemrosesan informasi yang didesain dengan menirukan cara 
kerja otak manusia dalam menyelesaikan suatu masalah dengan melakukan proses belajar melalui perubahan bobot sinapsisnya. Jaringan syaraf tiruan mampu mengenali kegiatan dengan berbasis masa lalu. Data masa lalu akan dipelajari oleh jaringan syaraf tiruan sehingga mempunyai kemampuan untuk memberi keputusan terhadap data yang belum pernah dipelajari. (Agustin \& Prahasto, 2012)

\section{METODE PENELITIAN}

\section{Jaringan Syaraf Tiruan}

Jaringan syaraf tiruan (JST) adalah paradigma pemrosesan suatu informasi yang terinspirasi oleh sistem sel syaraf biologi. JST dibentuk sebagai generalisasi model matematika dari jaringan syaraf biologi (Agustin \& Prahasto, 2012).

Backpropagation merupakan model JST dengan layer yang jamak, Backpropagation melatih jaringan untuk mendapatkan keseimbangan antara kemampuan jaringan mengenal pola yang digunakan selama pelatihan serta kemampuan jaringan untuk memberikan respon yang benar terhadap pola masukan yang serupa dengan pola yang dipakai selama pelatihan (Suhendra \& Wardoyo, 2015). Backpropagation merupakan algoritma pelatihan yang cukup popular hal ini dikarenakan backpropagation mempunyai kemampuan mengatasi permasalahan dalam pelatihan klasifikasi dengan skala data yang besar.

Tahap-tahap yang dilakukan penulis untuk tercapainya hasil penulisan ini adalah antara lain sebagai berikut:

\section{Memilih Dataset}

Memilih dataset yang tepat adalah langkah awal yang harus dilakukan, untuk memperoleh hasil yang akurat dan kredibel yang sangat penting untuk hasil akhir penulisan ini. Dataset mobil yang digunakan yaitu mengambil dari data source UCI Dataset Repository.

\section{Studi Pustaka}

Studi kepustakaan dilakukan penulis untuk membandingkan penelitian yang sudah ada dan penelitian yang penulis lakukan demi mencapai hasil penelitian terbaik dan menjadikan acuan penulis untuk melakukan penulisan ini.

\section{Memilih Metode Klasifikasi}

Dalam dataset ini yang mengandung beberapa parameter dan 1 attribut class yaitu acceptance. Penulis memutuskan menggunakan Neural Network sbagai metode klasifikasinya.

\section{Mengolah Data Awal}

Data awal yang didapatkan diolah kembali agar dapat diolah di RapidMiner dengan mudah yaitu dengan mengolah dengan acceptance unacc menjadi 0 dan acc, good, v-good menjadi 1 , serta pemetaan beberapa attribute sebagai berikut.

Table 1. Data Awal

\begin{tabular}{cccccc}
\hline buying & maintenance & Doors & persons & lug_boot & safety \\
\hline v-high & v-high & 2 & 2 & small & low \\
\hline high & high & 3 & 4 & med & med \\
\hline med & med & 4 & more & big & high \\
\hline low & low & 5-more & & &
\end{tabular}

Sumber: (Dirgantara, Herdyansyah, \& Rasenda, 2019)

Table 2. Data Olahan

\begin{tabular}{cccccc}
\hline Buying & maintenance & doors & persons & lug_boot & safety \\
\hline 4 & 4 & 2 & 2 & 1 & 1 \\
\hline 3 & 3 & 3 & 4 & 2 & 2 \\
\hline 2 & 2 & 4 & 5 & 3 & 3 \\
\hline 1 & 1 & 5 & & &
\end{tabular}

Sumber: (Dirgantara et al., 2019)

\section{Percobaan dan Pengujian Model}

Percobaan penelitian ini penulis lakukan dengan tools RapidMiner 9.0 menggunakan metode Neural Network atau Jaringan Syaraf Tiruan.

\section{Evaluasi dan Validitas (Result Evaluation)}

Pada evaluasi dan validitas ini akan membahas tentang evaluasi dari hasil percobaan yang telah dilakukan. Pengujian dari implementasi dengan menggunakan model ROC Curve (AUC) adalah gambar curve yang membedakan antara kelas berbeda sedangkan confusion matrix adalah akurasinya.

\section{a. Mengukur Menggunakan ROC Curve}

ROC Curve adalah kurva ROC yang banyak digunakan para peneliti untuk menilai hasil prediksi. Kurva ROC menggambatkan kinerja klasifikasi tanpa memperhatikan distribusi kelas atau kesalahan, pada sumbu vertical menggambarkan nilai positif (TP) dan sumbu horizontal menandakan nilai negative (FP) (Sucipto, 2012)

Untuk dapat melihat akurasi secara manual dilakukan perbandingan klasifikasi menggunakan curva ROC hasil ekspresi dari confusion matrix. Kurva ROC (Receiver Operating Characteristic) 
adalah cara lain untuk mengevaluasi akurasi dari klasifikasi secara visual (Vercellis, 2009).

Berikut merupakan contoh grafik curve ROC

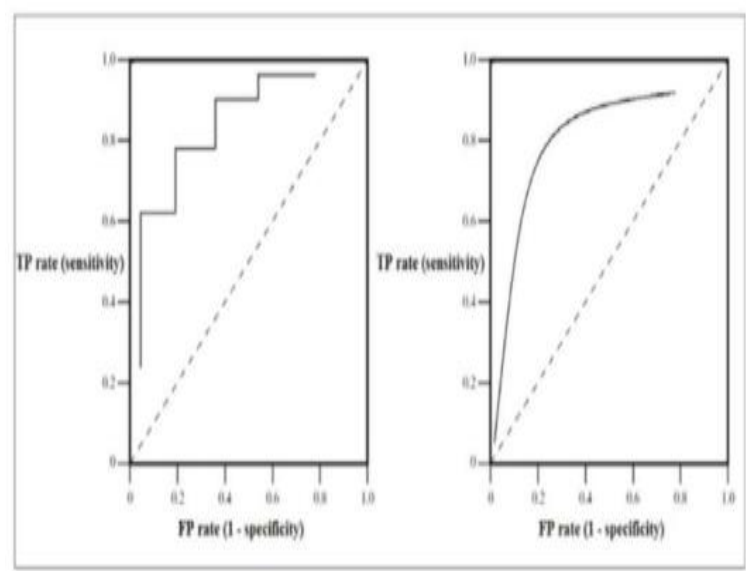

Sumber: (Sucipto, 2012)

Gambar 1. Contoh Grafik ROC

\section{b. Mengukur Menggunakan ROC Curve}

Confusion matrix merupakan sebuah table yang terdiri dari banyaknya baris data uji yang diprediksi benar dan tidak benar oleh model klasifikasi (Ariawan, 2011). Penulis membuat rumusan yang dipermudah untuk diingat dengan table sebagai berikut:

Table 3. Confusion Matrix

\begin{tabular}{cccc}
\hline \multirow{2}{*}{ Hasil Kelas } & \multicolumn{3}{c}{ Prediksi Kelas } \\
\cline { 2 - 4 } & & Class 0 & Class 1 \\
\hline \multirow{2}{*}{ Class 0 } & A & B \\
\cline { 2 - 4 } & Class 1 & C & D \\
\hline
\end{tabular}

Sumber: (Dirgantara et al., 2019)

Dengan perhitungan akurasi:

Accuracy $=\frac{(A+D)}{(A+B+C+D)} \times 100 \%$

Table 4. Precission and Recall

\begin{tabular}{rcc}
\hline & Relevant & Not Relevant \\
\hline Retrieved & $\mathrm{A}$ & $\mathrm{B}$ \\
\hline Not Retrieved & $\mathrm{C}$ & $\mathrm{D}$ \\
\hline
\end{tabular}

Sumber: (Dirgantara et al., 2019)

\section{Menarik Kesimpulan}

Dataset yang telah terolah menggunakan RapidMiner dengan metode yang telah digunakan maka dapat disimpulkan tinggi atau tidaknya akurasi pada hasil tersebut. Sehingga dapat dilakukan pertimbangan pada saat melakukan pembelian stok untuk penjualan mobil.

\section{HASIL DAN PEMBAHASAN}

\section{Hasil Akhir}

Setelah penulis melakukan penelitian menggunakan algoritma jaringan syaraf tiruan atau neural network untuk memprediksi penerimaan menggunakan dataset yang penulis dapatkan dari UCI Repository yang terdapat attribute-nya yaitu buying, maintenance, doors, persons, lug boot dan safety. Yang mana ada 1728 data. Penulis melakukan training, learning sampai dengan proses testing pada penelitian ini Dimana dari hasil dataset sebanyak ini proses yang dimulai dari testing didapatkan hasil penelitial dengan akurasi prediksi sebesar 98,26\% +/- 0,73\% dan AUC sebesar $0.999+/$ -

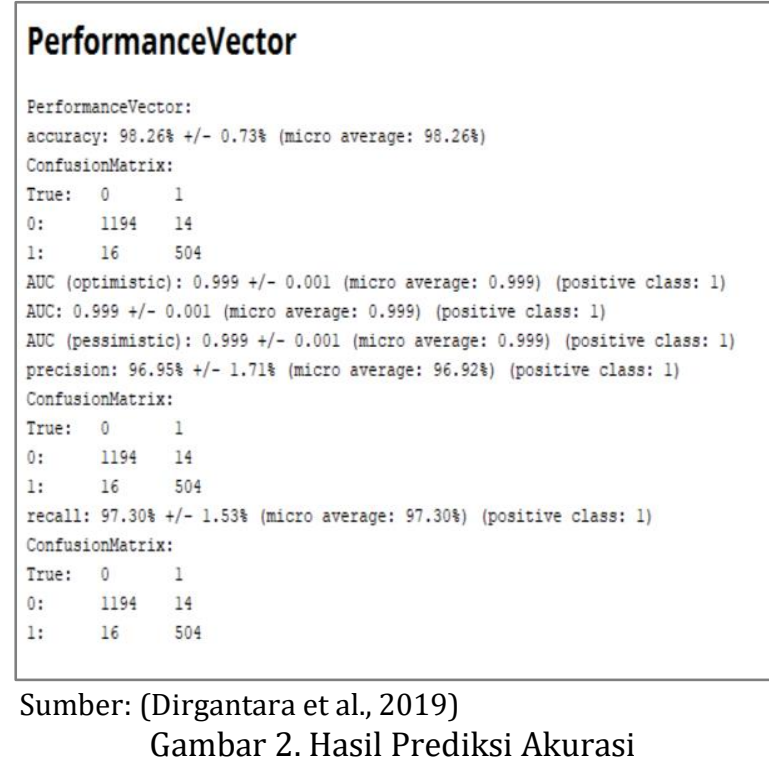

\section{Pembahasan Penelitian}

Setelah tahapan proses pengumpulan data dan pengolahan data maka yang harus dilakukan adalah membuat modelnya dengan tools RapidMiner dengan dataset yang telah didapat di UCI Repository sebelumnya sebanyak 1728 data dengan tahapan dan proses yang dimulai dari tahap pemodelan, training, learning dan testing.

1. Proses Pemodelan

Di sini penulsi memilih menggunakan pengujian menggunakan cross validation model. Penulis menghubungkan dataset yang didapatkan dari UCI Repository sebelumnya lalu dihubungkan ke cross validation model. 


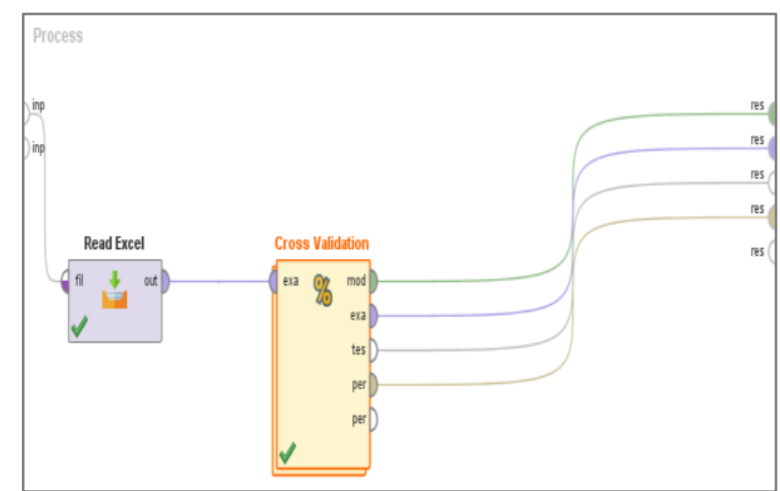

Sumber: (Dirgantara et al., 2019)

Gambar 3. Pemodelan Jaringan Syaraf Tiruan Menggunakan Cross Validation

\section{Proses Training}

Proses ini adalah proses yang ada di dalam Cross Validation. Prosesnya training model pada jaringan syaraf tiruan ini menggunakan 200 training cycles, 0.01 learning rate dan 0.9 momentum.

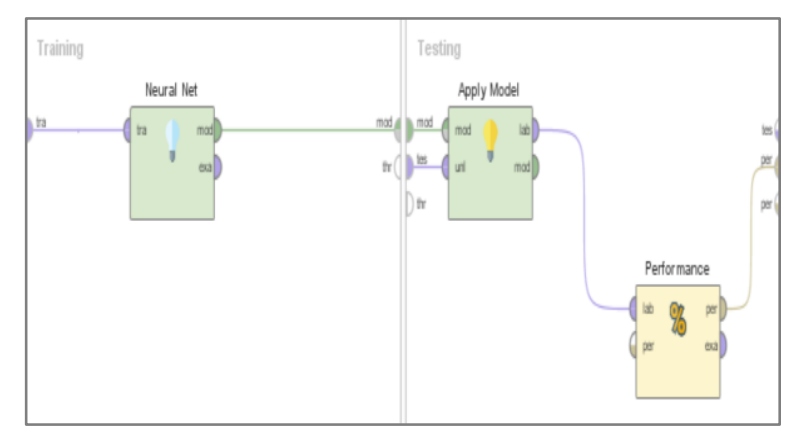

Sumber: (Dirgantara et al., 2019)

Gambar 4. Training dan Learning pada Cross Validation

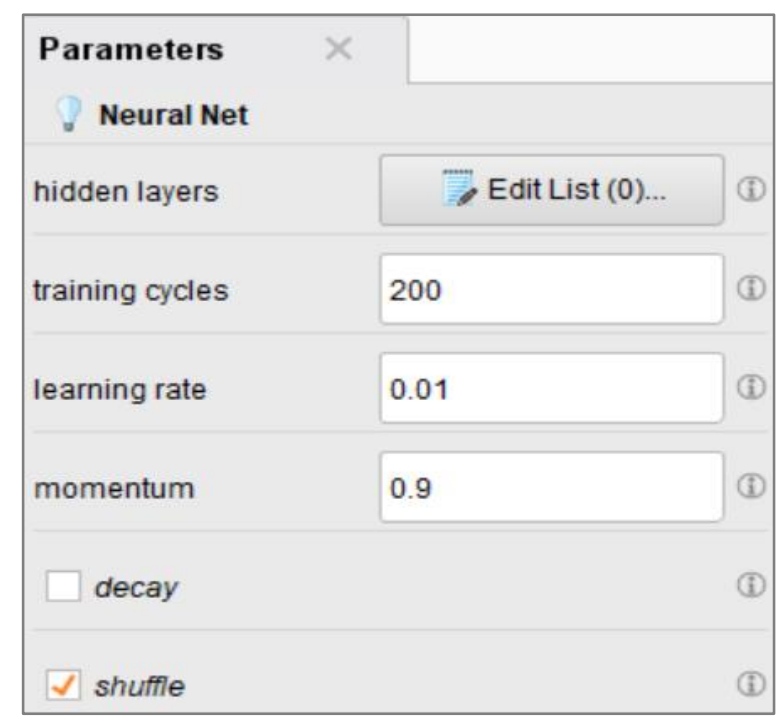

Sumber: (Dirgantara et al., 2019)

Gambar 5. Parameter Neural Network

\section{Proses Testing}

Proses testing dilakukan dengan cara insert apply model dan performance seperti gambar sebelumnya dan dengan parameter AUC dan main criterion.

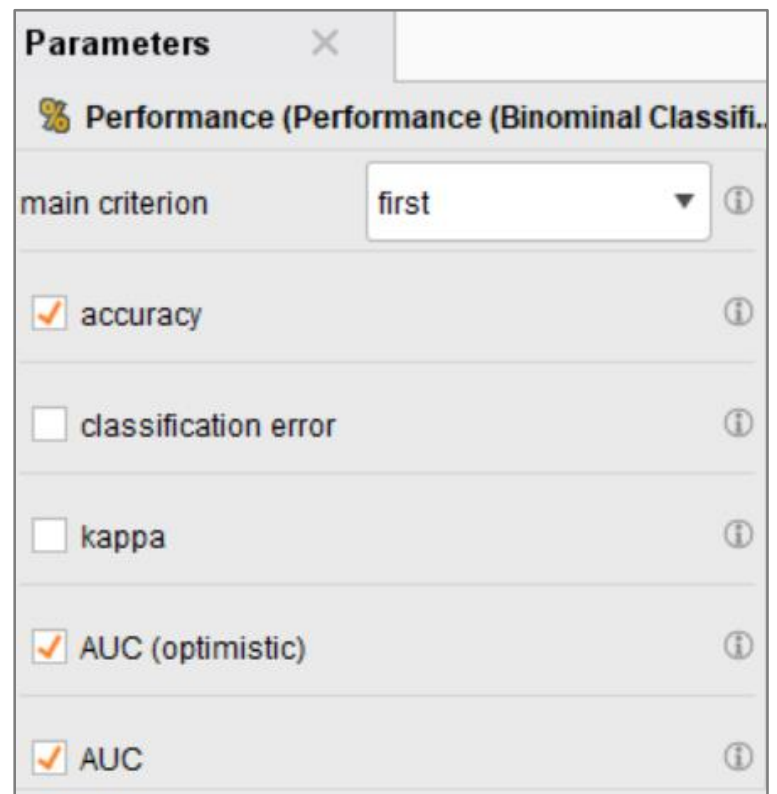

Sumber: (Dirgantara et al., 2019)

Gambar 6. Parameter Performance

4. Hasil Testing

Lakukan eksekusi pada RapidMiner, pilih Results, Performance, lalu Description maka akan muncul hasil tersebut.

\section{PerformanceVector}

\section{PerformanceVector:}

accuracy: $98.26 \%$ +/- $0.73 \%$ (micro average: $98.26 \%$ )

Sumber: (Dirgantara et al., 2019)

Gambar 7. Performance Vector Description Result

\section{Evaluasi dan Validasi Hasil (Result Evaluation)}

1. Pengujian Kurva ROC

Nilai Area Under Curve atau disebut juga sebagai nilai AUC dengan algoritma jaringan syaraf tiruan dapat dilihat pada gambar di bawah. Nilai AUC yang didapatkan penulis saat ini yaitu berkisar 0,999+/-. 


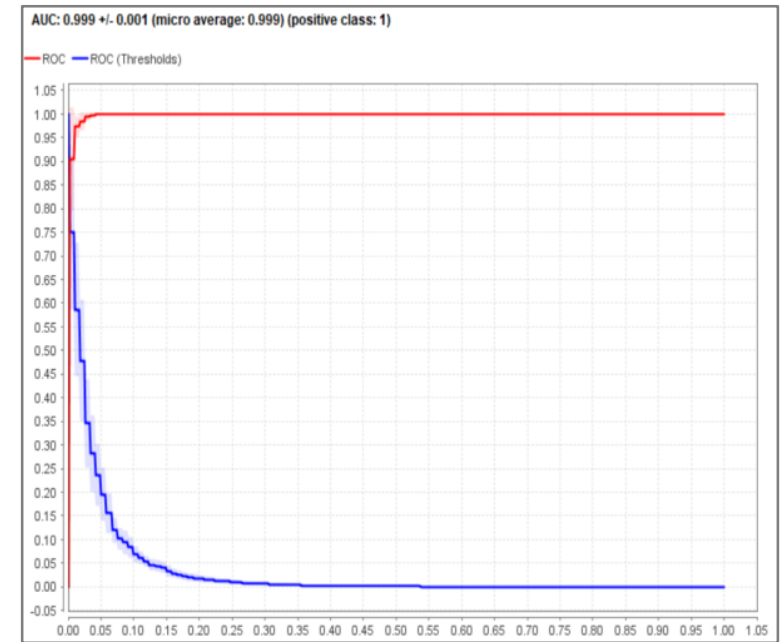

Sumber: (Dirgantara et al., 2019)

Gambar 8. AUC Performance

1. Pengujian Confusion Matrix

Klik Result, PerformanceVector, Performance lalu accuracy, maka pada RapidMiner bisa dilihat melalui table view sebagai berikut.

\begin{tabular}{|c|c|c|c|}
\hline \multicolumn{4}{|c|}{ accuracy: $98.26 \%+1-0.73 \%$ (micro average: $98.26 \%)$} \\
\hline & true 0 & toe 1 & dass precision \\
\hline predo 0 & 1194 & 14 & $98.84 \%$ \\
\hline pred. 1 & 16 & 504 & $96.92 \%$ \\
\hline dass recall & $98.68 \%$ & $97.30 \%$ & \\
\hline
\end{tabular}

Sumber: (Dirgantara et al., 2019)

Gambar 9. Confusion Matrix

Dari gambar di atas maka dapat disimpulkan sebagai berikut:

$$
\begin{array}{ll}
A=1194 & B=14 \\
C=16 & D=504
\end{array}
$$

Accuracy $=\frac{(A+D)}{(A+B+C+D)} \times 100 \%$

$$
\begin{aligned}
\text { Accuracy } & =\frac{(1.194+1.698)}{(1.194+14+16+504)} \times 100 \% \\
& =\frac{(1.698)}{(1.728)} \times 100 \% \\
& =0.9826 \\
& =98,26 \%
\end{aligned}
$$

Berdasarkan hasil kesimpulan yang dihitung diatas, maka tingkat akurasi jaringan syaraf tiruan adalah sebesar $98.26 \%$

\section{SIMPULAN DAN SARAN}

Dari hasil penelitian yang dijelaskan sebelumnya penulis melakukan percobaan dengan menggunakan RapidMiner metode jaringan syaraf tiruan atau neural network dengan dataset yang diambil dari UCI Repository sebanyak 1.728 data dengan tingkat akurasi sebesar $98.26 \%$ dan AUC $0,999+/-$.

\section{DAFTAR REFERENSI}

Agustin, M., \& Prahasto, T. (2012). Penggunaan Jaringan Syaraf Tiruan Backpropagation Untuk Seleksi Penerimaan Mahasiswa Baru Pada Jurusan Teknik Komputer Di Politeknik Negeri Sriwijaya. JURNAL SISTEM INFORMASI BISNIS, $2(2)$. https://doi.org/10.21456/vol2iss2pp089097

Ariawan, I. (2011). Kurva Receiver Operating Characteristic. Retrieved from https://id.scribd.com/doc/15123416/KurvaReceiver-Operating-Characteristic

Dirgantara, A., Herdyansyah, S., \& Rasenda, R. (2019). Laporan Penelitian: Klasifikasi Penerimaan Mobil Bekas Berdasarkan Metode Neural Network. Jakarta.

Guntoro, G., Costaner, L., \& Lisnawita, L. (2019). Prediksi Jumlah Kendaraan di Provinsi Riau Menggunakan Metode Backpropagation. Nformatika Mulawarman: Jurnal Ilmiah Ilmu Komputer, 14(1), 51-57. Retrieved from http://e-

journals.unmul.ac.id/index.php/JIM/article/v iew/1745

Pakaja, F., Naba, A., \& Purwanto, P. (2012). Peramalan Penjualan Mobil Menggunakan Jaringan Syaraf Tiruan dan Certainty Factor. Jurnal EECCIS, 6(1), 23-28. Retrieved from https://jurnaleeccis.ub.ac.id/index.php/eecci s/article/view/162

Sucipto, A. (2012). CREDIT PREDICTION WITH NEURAL NETWORK ALGORITHM Ir . Adi Sucipto , M . Kom . Sains and Technology Faculty Universitas Islam Nahdlatul Ulama Jepara, (15), 978-979.

Suhendra, C. D., \& Wardoyo, R. (2015). Penentuan Arsitektur Jaringan Syaraf Tiruan Backpropagation (Bobot Awal dan Bias Awal) 
Menggunakan Algoritma Genetika. IJCCS

(Indonesian Journal of Computing and Cybernetics Systems), 9(1), 77. https://doi.org/10.22146/ijccs.6642

Vercellis, C. (2009). Business Intelligence: Data Mining and Optimization for Decision Making. Business Intelligence: Data Mining and Optimization for Decision Making. https://doi.org/10.1002/9780470753866 